MIDAS

Museus e estudos interdisciplinares

2 | 2013

Varia

\title{
Ana Carvalho - Os Museus e o Património Cultural Imaterial: Estratégias para o Desenvolvimento de Boas Práticas
}

Ana Botas

\section{(2) OpenEdition}

Journals

Edição electrónica

URL: http://journals.openedition.org/midas/292

DOI: $10.4000 /$ midas.292

ISSN: 2182-9543

Editora:

Alice Semedo, Paulo Simões Rodrigues, Pedro Casaleiro, Raquel Henriques da Silva, Ana Carvalho

Refêrencia eletrónica

Ana Botas, « Ana Carvalho - Os Museus e o Património Cultural Imaterial: Estratégias para o Desenvolvimento de Boas Práticas », MIDAS [Online], 2 | 2013, posto online no dia 03 abril 2013, consultado no dia 22 setembro 2020. URL : http://journals.openedition.org/midas/292 ; DOI : https:// doi.org/10.4000/midas.292

Este documento foi criado de forma automática no dia 22 setembro 2020.

\section{(c) (i) (3)}

Midas is licensed under a Creative Commons Attribution-NonCommercial-ShareAlike 3.0 International License 


\title{
Ana Carvalho - Os Museus e o Património Cultural Imaterial: Estratégias para o Desenvolvimento de Boas Práticas
}

\author{
Ana Botas
}

\section{REFERÊNCIA}

Carvalho, Ana. 2011. Os Museus e o Património Cultural Imaterial: Estratégias para o Desenvolvimento de Boas Práticas. Lisboa: Edições Colibri e CIDEHUS-Universidade de Évora. 196 páginas, ISBN: 978-989-689-169-5.

1 Ana Carvalho é museóloga e investigadora do Centro Interdisciplinar de História, Culturas e Sociedades da Universidade de Évora (CIDEHUS-Universidade de Évora) desde 2007. Dá atualmente continuidade à sua pesquisa em torno dos museus e da diversidade cultural, no âmbito do seu projeto de doutoramento e enquanto bolseira da Fundação para a Ciência e a Tecnologia (FCT). É autora do blogue galardoado com um prémio APOM, No Mundo dos Museus, no qual dá destaque a notícias da atualidade na área da museologia em Portugal.

2 Este livro resulta da publicação da sua dissertação de mestrado em museologia realizada na Universidade de Évora, defendida em 2009, e revista para publicação em 2011.

3 Este trabalho tem como ponto de partida uma reflexão em torno dos desafios que se colocam aos museus portugueses na sequência do crescente debate promovido pela UNESCO em torno da salvaguarda do património, conceito que ao nível político tem vindo a ganhar novos contornos, alargando-se a manifestações da esfera do imaterial, e que culminou na adoção da Convenção para a Salvaguarda do Património Cultural Imaterial, em 2003. Na sequência da sua ratificação pelo Estado português em 2008, foi atribuído 
ao recém-criado Instituto dos Museus e da Conservação, através do Departamento do Património Imaterial, a responsabilidade de dar cumprimento às diretrizes internacionais no domínio das políticas de salvaguarda do património e de acompanhar o desenvolvimento de legislação específica nacional nesta área.

4 É neste sentido que a autora justifica a necessidade de aprofundar este tema relacionando-o com os museus. Para além do reconhecimento dos museus como agentes importantes na salvaguarda deste tipo de património pelo ICOM, a tutela organizacional atribuída a este domínio em Portugal coloca claramente as instituições museológicas no cerne do trabalho a desenvolver nesta área. Algumas das questões que este trabalho pertinentemente levanta prendem-se precisamente com a real capacidade dos museus em corresponderem a esta demanda. De facto, os museus poderiam apresentar-se inquestionavelmente como atores privilegiados neste processo, pelas competências e procedimentos no domínio do património que já têm instituído; no entanto, o que a autora nos demonstra e justifica, é que a prática museológica tem revelado um maior pendor para a cultura material pondo em evidência previsíveis dificuldades para os museus neste domínio.

5 Apresentado introdutoriamente o tema do seu trabalho, sucedem-se três capítulos nos quais a autora desenvolve, respetivamente, o enquadramento histórico do trabalho desenvolvido pela UNESCO ao nível do património que conduziu à Convenção de 2003; enfoque no contexto nacional e nas consequências no quadro normativo português do alargamento da noção de património aos domínios do imaterial; e finalmente, uma reflexão sobre o papel dos museus na salvaguarda do património imaterial, com algumas linhas orientadoras a ter em conta pelos museus, a partir de alguns estudos de caso exemplificativos de boas práticas.

6 Como a autora bem destaca, a designação de património cultural imaterial (PCI) não é mais do que um conceito de natureza política que não traz noções novas ao modo como já vinha sendo entendido o património, nomeadamente em áreas do saber como a antropologia. Para esta os bens materiais já eram parte inalienável de um sistema mais alargado, composto pelo conjunto das crenças, saberes, práticas, valores e tradições de uma dada comunidade, distinguindo-a de outras, constituindo assim a diversidade cultural.

7 A autora percorre de forma cuidada as principais iniciativas e normativos desenvolvidos pela UNESCO que conduziram ao amadurecimento da Convenção de 2003, numa análise articulada com o contexto político em que foram surgindo, expondo ao mesmo tempo a gestação de conceções embrionárias de PCI subjacentes e as áreas de atuação que foram permanecendo lacunares.

8 Para além da atualização de um conceito que importava fazer, a promoção do debate em torno destas questões pela UNESCO, é também justificada neste livro pela necessidade política de cobrir as manifestações culturais que escapavam ao regime jurídico criado pela Convenção para a Proteção do Património Mundial, Cultural e Natural de 1972.

9 Apesar dos avanços importantes dados pela UNESCO em matéria do património que viria a ser designado de PCI, entre as quais se destacam a Recomendação para a Salvaguarda da Cultura Tradicional e do Folclore em 1989, o Programa das Línguas em Perigo e o Programa Tesouros Humanos Vivos, em 1993; nenhuma foi tão marcante para o PCI, quanto a Convenção de 1972 o foi para o património material. O Programa da Proclamação das Obras Primas do Património Oral e Imaterial da Humanidade, em 1997, é aqui 
apontada como a medida que mais atenção terá feito recair sobre o PCI ao nível internacional.

10 Em matéria de legislação nacional, a autora introduz a Lei n. 13/85 com um caráter inovador, na medida em que já contemplava na sua noção de património cultural, não apenas os bens materiais, mas também os imateriais. Esta veio a ser revogada pela Lei n.. 107/2001, mais ambiciosa e com posteriores desenvolvimentos em 2009, com o Decreto-Lei n..$^{139 / 2009}$ que estabelece o regime jurídico de salvaguarda do PCI, e em 2010, com a Portaria n. ${ }^{\circ} 196$ a regulamentar os procedimentos administrativos para a submissão de candidaturas ao Inventário Nacional do Património Cultural Imaterial.

$11 \mathrm{Na}$ análise detalhada que a autora faz do quadro jurídico nacional, perpassa a noção de que este acompanhou os desenvolvimentos internacionais nesta matéria, seguindo bem de perto a Convenção de 2003 no que se refere aos vários domínios entendidos como PCI, à importância do papel ativo das comunidades ou grupos de pertença desse património nas medidas de salvaguarda e à obrigatoriedade da realização de inventários.

12 No contexto da museologia, a autora acompanha as principais orientações do ICOM que vêm naturalmente corroborar o apoio deste à Convenção, focando a necessidade dos museus se desviarem de uma linha de trabalho mais focada na cultura material. Nesse sentido, são referidas iniciativas diversas: a que deu origem à Carta de Shangai (2002), com as suas recomendações dirigidas ao trabalho dos museus neste domínio; a escolha do tema Museums and Intangible Heritage para o Dia Internacional dos Museus (2004); a Declaração de Seoul (2004) e as suas resoluções assentes na ideia do PCI como garante da preservação da diversidade cultural, a criação da publicação International Journal of Intangible Heritage (2004) e o trabalho desenvolvido pelos vários comités do ICOM, com destaque aqui para o ICTOP, nomeadamente pela revisão que este fez em 2008 do ICTOP - Curricula Guidelines for Professional Development, alargando as competências atribuídas aos profissionais dos museus com novas valências no domínio do PCI e contemplando menções a este em todas as funções museológicas "este documento propõe uma visão do património que integra o $\mathrm{PCI}$, entendido como um princípio-base de atuação e parte fundamental das estratégias e políticas museológicas, e que, por sua vez, é incorporado em todas as atividades, desde investigação, interpretação, comunicação e educação" (p. 109). Exceção é feita ao CIDOC no domínio das recomendações para a documentação nos museus que ainda não terá ido tão longe num dos seus documentos de referência Statement of Principles of Museum Documentation (2007) no qual ainda se constata uma ausência de alusões explícitas ao PCI.

13 A autora avança com uma exposição realista das dificuldades que acometem muitos museus e que não favorecem a atuação pretendida em relação ao $\mathrm{PCI}$, das quais destacamos: a ausência de uma alusão ao PCI na missão da maioria dos museus, resultado de um trabalho tradicionalmente centrado nas coleções; os recursos humanos, técnicos e financeiros limitados; risco de cristalização de um património por natureza, vivo e dinâmico, pela sua sujeição a procedimentos técnicos de inventário já normalizados mas vocacionados para bens materiais; necessidade de formação específica; e recorrência da distância entre os museus e as comunidades, apesar de já não ser nova a ideia da participação da comunidade no museu, muito defendida pela chamada nova museologia.

14 Atendendo à complexidade e extensão que o PCI adquire e às limitações de cada museu, Ana Carvalho simplificou três abordagens distintas possíveis, no modo dos museus 
poderem atuar neste domínio de acordo com as suas características: enquanto catalisadores, partindo do museu a mobilização das comunidades e a sensibilização para a salvaguarda do PCI; enquanto mediadores, cabendo-lhes a coordenação de projetos ou o apoio a projetos em curso nas comunidades; e enquanto espaço em si mesmo, disponibilizando os seus recursos (salas de exposição, arquivos, equipamento audiovisual) ao serviço da comunidade.

Destacando algumas áreas de atuação dos museus, designadamente o inventário e documentação, a investigação, as exposições, a educação e o uso de novas tecnologias, a autora aponta ainda de uma forma otimista as potencialidades que contêm, ilustrandoas com alguns exemplos de casos de boas práticas, no panorama nacional e internacional, que revelam experiências bem-sucedidas.

16 Ainda que no plano institucional seja o Instituto dos Museus e da Conservação a entidade responsável em Portugal pela implementação das orientações da UNESCO em matéria de PCI, este trabalho coloca em evidência a necessidade da criação de redes entre parceiros de diferentes naturezas, entre eles os museus, caso contrário, correr-seá o risco de não se conseguir abranger um património tão vasto.

\section{AUTORES}

\section{ANA BOTAS}

Museu Nacional de Etnologia, Portugal, ana.botas@hotmail.com 